American Journal of Infectious Diseases 5 (2): 74-82, 2009

ISSN 1553-6203

(C) 2009 Science Publications

\title{
Identification of Clonal Clusters of Klebsiella pneumoniae Isolates from Chennai by Extended Spectrum Beta Lactamase Genotyping and Antibiotic Resistance Phenotyping Analysis
}

\author{
${ }^{1}$ C. Kamatchi, ${ }^{1} \mathrm{H}$. Magesh, ${ }^{2}$ Uma Sekhar and ${ }^{1}$ Rama Vaidyanathan \\ ${ }^{1}$ Department of Industrial Biotechnology, Dr. M.G.R. Educational and Research Institute, \\ E.V.R. Periyar Salai, Maduravoyal, Chennai-600 095, Tamil Nadu, India \\ ${ }^{2}$ Department of Microbiology, Sri Ramachandra University, Porur, Chennai
}

\begin{abstract}
Problem statement: An increased resistance to antibiotics has been reported in Klebsiella pneumoniae, an opportunistic gram negative pathogen belonging to Entrobacteraceae due to the evolution and spread of plasmid encoded extended spectrum beta lactamases and other genes conferring cross-resistance to other antibiotics. This is of concern due to the increasing cost of antibiotic treatment and the spread of multidrug resistance to more pathogenic microorganisms. This study was undertaken to analyze the extent of the problem, to identify the most prevalent MDR isolates of Klebsiella pneumoniae in Chennai and to identify new plant based drugs. Approach: About 188 clinical isolates of Klebsiella pneumoniae were collected from Chennai during the period Nov. 2007Oct. 2008 and their resistance to different groups of antibiotics were analyzed. These isolates were further characterized by molecular studies to identify the ESBL genes conferring the resistance phenotype. Plant extracts were tested against the MDR isolates to identify new treatment methods. Results: Our results showed that the combination therapy of clavulanic acid with cephalosporins and fluroroquinolones-norfloxacin and ciprofloxacin were the most effective antibiotics for treatment of Klebsiella pneumoniae infections. However resistance to clavulanic acid was increasing among the isolates (17\%). All the isolates harbored a plasmid containing one or more of the genes for ESBL resistance. Plasmid isolation from the Isolates followed by ESBL PCR genotyping showed that CTX$\mathrm{M}$ was present in $75 \%$ isolates and TEM in 73\% isolates either alone or in combination with the other ESBL genes. SHV ESBL type was present only in $42 \%$ of isolates. We identified 4 presumptive clonal spreads which were likely to be prevalent in India by clustering based on ESBL genotypic and antibiotic resistance. The isolates with both SHV and CTX were correlated with the most pathogenic and clavulanic acid resistant isolates. The extracts of Hemidesmus indicus and Terminalia arjuna had a significant antimicrobial activity against the MDR isolates. Conclusion: There was an increase in the spread of the ESBL genes and clavulanic acid resistance in the clinical isolates of Klebsiella pneumoniae in Chennai. Our data also supported a higher incidence of CTX-M genotype in India though the SHV genotype was associated with the most resistant forms of ESBL. Future research with separation of plant extracts to identify bioactive principles will pave the way for newer plant based antibiotics.
\end{abstract}

Key words: Klebsiella pneumoniae, ESBL, TEM, SHV, CTX-M, multi-drug resistant, Hemidesmus indicus, Terminalia arjuna

\section{INTRODUCTION}

Klebsiella pneumoniae is an opportunistic pathogen that causes a significant proportion of hospital-acquired urinary tract infections, pneumonia, septicemias and soft tissue infections ${ }^{[1]}$. Studies have shown that Extended-Spectrum Beta-Lactamase (ESBL)-producing Klebsiella pneumoniae have rapidly spread worldwide and pose a serious threat for health care-associated infections ${ }^{[1]}$. Increasingly the ESBL Klebsiella pneumoniae are also showing co-resistance to quinolones and aminoglycoside antibiotics ${ }^{[5,6]}$ present in plasmids which can be transferred by conjugation to other strains.

The resistance to antibiotics can be of the following types (1) Drug inactivation by degradation or

Corresponding Author: Rama Vaidyanathan, Department of Industrial Biotechnology, Dr. M.G.R. Educational and Research Institute, E.V.R. Periyar Salai, Maduravoyal, Chennai-600 095, Tamil Nadu, India 
modification enzymes such as beta lactamaces and aminoglycoside transferases, (2) Alteration of the drug target (3) Emergence of a bypass pathway not inhibited by the drug (4) Reduced membrane permeability for the drug (5) Drug efflux from the cells. Resistance due to drug efflux can result in multi-drug resistance. These genes can be present in the chromosome or plasmid within integrons which help in horizontal transfer of the antibiotic resistance.

Beta lactam antibiotics disrupt the synthesis of the peptidoglycan layer of bacterial cell walls by mimicing a portion of the bacterial peptidoglycan interfering with the action of the transpeptidase enzymes. Continued use of cephalosporins have resulted in the emergence of resistance. The most common mechanism of resistance to beta lactam antibiotics is the production of chromosomal or plasmid encoded beta-lactamase enzyme that catalyze the hydrolysis of beta-lactam C-N bond of the antibiotics to give the corresponding betaamino acid devoid of antibacterial activity ${ }^{[7]}$. Extended Spectrum Beta Lactamases (ESBLs) are a group of enzymes that can hydrolyze the oxyiminocephalosporins such as cefotaxime, ceftazidime, cefepime). There are more than 200 subtypes of ESBL which are believed to have evolved from a few common ancestral types. The most common ESBL enzymes belong to TEM, SHV, CTX-M and OXA types. From these ESBL enzymes, amino acid substitutions have lead to high spectrum of ESBL subtypes with changes in isoelectric $\mathrm{pH}$ and substrate specificity. The ESBL genes occur in plasmids within integrons which aid in capturing genes conferring resistance to other antibioitcs.

Fluoroquinolones are powerful broad-spectrum antimicrobial agents used for the treatment of a wide variety of community-acquired and nosocomial infections including ESBL infections. The prototype quinolone is nalidixic acid and the other commonly used fluroroquinolone derivatives include ciprofloxacin, norfloxacin and levofloxacin. These chemicals inhibit topoisomerase II, a DNA gyrase and DNA topoisomerase IV to inhibit DNA replication. Fluoroquinolone resistance arises through specific mutations within the target proteins DNA gyrase and topoisomerase IV, at position 83 or 87 within DNA gyrase $\mathrm{A}$ and position 80 or 84 within the ParC subunit of topoisomerase IV. Energydependent efflux and porin loss have also been shown to confer a fluoroquinolone resistance phenotype in $K$. pneumoniae ${ }^{[8]}$. Plasmid-mediated resistance mechanisms to fluoroquinolone due to qnrA which encodes a 218 amino acid protein of the pentapeptide family that protects DNA gyrase from quinolone inhibition has also been reported ${ }^{[9]}$.

Other groups of antibiotics that is used is amikacin, which inhibits protein synthesis by binding to the $30 \mathrm{~S}$ ribosomal subunit to prevent the formation of an initiation complex with messenger RNA. Amikacin resistance in Klebsiella is due to the presence of aac (6')-Ib gene which encodes many variants of an aminoglycoside-acetyltransferase enzyme first cloned from pMET1 an MDR plasmid in Klebsiella ${ }^{[2]}$. Trimethoprim is an antimetabolite antibiotic which binds to dihydrofolate reductase and inhibit formation of tetrahydrofolic acid. Trimethoprim rsistance is mediated by a mutant dydrofolate reductase gene which is insensitive to Trimethoprim.

These antibiotic resistance genes present within integrons giving a selective advantage to these isolates leading to the clonal spread these highly resistant pathogens. In addition the integorns can also capture more resistance determinants. Therefore it is very important to identify the prevalent clones of resistant isolates and characterize the plasmids present in the antibiotic resistant isolates. Regular monitoring of antibiotic resistance patterns are essential in deciding the effective antibiotics for healthcare regimes.

\section{MATERIALS AND METHODS}

Bacterial isolates: One hundred eighty eight clinical isolates of Klebsiella pneumonia collected from tertiary care hospitals during Nov. 2007-Oct. 2008 and were subjected to routine culture and antibiotic susceptibility testing. Each isolate was stored as a glycerol stock in the- $20^{\circ} \mathrm{C}$. The isolates of Klebsiella pneumonia were collected from different sources-urine-66 sputum and pus 115 and blood-7.

Antibiotic susceptibility test: Antibiotic susceptibility testing was performed according to standard methods ${ }^{[11]}$ on Mueller Hilton agar (Hi media).The antibiotics used $\left(\mu \mathrm{g} \mathrm{disk}^{-1}\right)$ were ampicillin $\left(30 \mu \mathrm{g} \mathrm{mL}^{-1}\right)$, piperacillin, Norfloxacin (10), Nalidixic acid (30), Ciprofloxacin (30), Levofloxacin (5), Chloramphenicol (30), Amikacin (30), Trimethoprim (30), Cefomandole (30), Cefoperzone (75), Cefoxitin (30), Ceftazidime (30), Cefotaxime (30) and Amoxyclav (30 mcg disc ${ }^{-1}$ ) were used for isolates from samples collected. The results were interpreted as per the guidelines of the NCCLS control $^{[12]}$.

Transconjugation experiments: Transconjugation experiments were performed for all isolates which 
showed resistant to amoxyclav. Transconjugation were performed according to standard methods ${ }^{[13]}$. Mating was performed with E. coli 1652 nalidixic acid resistant as recipient strain.Transconjugation was selected on Mac Conkey agar supplemented with nalidixic acid and cefotaxime.

Plasmid isolation: The selected isolates of $K$. pneumonia were for the presence of plasmid by alkaline lysis method $1^{[14]}$. Plasmid samples $10 \mu \mathrm{L}$ were electrophoresed through $0.7 \%$ agarose containing ethidium bromide $2 \mu \mathrm{L}$, with reference $1 \mathrm{~Kb}$ molecular weight were calculated with the help lab image software provided with gel documentation system.

Detection of ESBL gene by PCR: Plasmid DNA were detected for the presence for class A enzymes of ESBL using PCR.Primers for Class A enzymes TEM/F: 5'ATAAAATTCTTGAAGAAGACGAAA-3, TEM/R 5'-GACAGTTACCAATGCTTAATC-3'; SHV/F: 5'TCGTTATGCGTTATATTCGCC-3', SHV/R5'GGTTAGCGTTGCCAGTGCT-3'; CTX-M/F-5'CGCTTTGCGATGTGCAG-3' and CTX-M/R: 5'ACCGCGATATCGTTGGT-3' were used for the amplification of bla genes ${ }^{[15]}$.

Clustering of antibiotic resistant isolates: The Resistance response to each antibiotic was given a score of 1 while sensitivity or intermediate response was given 0 score. The isolates were first clustered based on their ESBL PCR reaction into 7 groups-those with only TEM, SHV or CTX-M and those with any two ESBL and those with all the three ESBL. Then they were clustered into similar group using the sort function of microsoft excel. Those with identical phenotypes were clustered into one group and identified as a probable single clonal spread.

Restriction pattern of plasmid: Restriction digestions were performed using Hind III and BamH I with selected isolates. About $2 \mu \mathrm{L}$ of enzymes were diluted by addition of $18 \mu \mathrm{L}$ of $10 \mathrm{x}$ assay buffer. Total working reaction mixture of restriction digestion were made up to $25 \mu \mathrm{L}$ with distilled water (DNase free water) included $8 \mathrm{uL}$ of sample plasmid DNA. This digestion showed variable plasmid profile.

Preparation of plant extracts: The selected medicinal plants were Punica granatum, Delonix regina, Hemidesmus indicus, Terminalia arjuna, Camellia sinensis, Holarrhena antidysentrica against ESBL producing organisms. Plant extract were prepared as described by Ahmed et al. ${ }^{[16]}$.Three hundred fifty grams of dry plant powder was soaked in $150 \mathrm{~mL}$ ethanol or ethyl acetate, 3-4 days. The extraction was passed through the filter paper and dried in water bath. The crude extract was prepared by dissolving known amount of dry extract in DMSO to have stock solution of $50 \mathrm{mg} \mathrm{mL}^{-1}$ concentration.

Plant activity against ESBL producing organisms: Antimicrobial assay was done by agar well dilution method $^{[17,18]}$ with control. Test organisms were diluted to $0.1 \mathrm{~mL}$ and spread on MHA plates. Well of $6 \mathrm{~mm}$ punched in agar medium and filled with $50 \mu \mathrm{L}$ of $10 \mathrm{mg} \mathrm{mL}$-1 concentration with blank (DMSO) separately and incubated for $37^{\circ} \mathrm{C}$ overnight. Zone of inhibition was measured in $\mathrm{mm}$.

\section{RESULTS}

A total of 188 isolates of Klebsiella pneumoniae were collected from urinary (66), blood (7), pus and sputum samples (115) from hospitals in Chennai during the time frame Nov 2007-Oct 2008. The isolates were tested against a total of 15 antibiotics belonging to the four classes of antibiotics based on their mechanism of action (Table 1). The antibiotic resistance patterns are shown in Table $2 a$ and $b$.

Plasmids from each isolate was isolated and a specific PCR was performed for the three types of ESBL (Fig. 1). The TEM PCR amplified a fragment of 1080 bp, CTX-M, 551 bp and SHV 861 bp. The isolates were scored for the specific amplification. A total of 152 isolates were scored for ESBL genotyping. The results are shown in Fig. 1 and Table 3.

The isolates were clustered based on their ESBL phenotype and response to different groups of antibiotics. Isolates with identical resistance pattern to the 15 antibiotics used and the 7 ESBL PCR types were clustered to identify clonal spreads. The data is shown in Table 4. Plasmids isolated from a few MDR cultures were analyzed by restriction digestion.

Four isolates were chosen to study the effect of antimicrobial extracts. The clearing zone obtained by using the plant antimicrobial extract is shown in Table 5. The extracts which gave the maximum clearing zone were taken as potential plants to study further. 
Am. J. Infect. Dis., 5 (2): 74-82, 2009

Table 1: The antibiotics used in this study and their mode of action

\begin{tabular}{|c|c|c|c|}
\hline Antibiotic group & Antibiotics used & Mode of action & \\
\hline $\begin{array}{l}\text { Beta lactam } \\
\text { antibiotics }\end{array}$ & $\begin{array}{l}\text { Ampicillin } \\
\text { Piperacillin } \\
2 \mathrm{G} \text { cephalosporins } \\
3 \text { G cephalosporins }\end{array}$ & $\begin{array}{l}\text { Cefoxitin } \\
\text { Cefamandole } \\
\text { Ceftazidime } \\
\text { Cefotaxime } \\
\text { Cefotaxime }\end{array}$ & $\begin{array}{l}\text { Beta lactams share structural similarity with bacterial cell wall } \\
\text { precursors and act as suicide substrates of the D,D-transpeptidase } \\
\text { catalytic domain of the penicillin binding proteins responsible for the } \\
\text { last cross-linking step of cell wall assembly. }\end{array}$ \\
\hline Quinolone & $\begin{array}{l}\text { Nalidixic acid } \\
\text { Ciprofloxacin } \\
\text { Norfloxacin } \\
\text { Levofloxacin }\end{array}$ & & $\begin{array}{l}\text { Inhibit DNA topoisomerase II or DNA gyrase to inhibit DNA replication } \\
\text { and repair. }\end{array}$ \\
\hline Metabolic inhibitor & Trimethoprim & & $\begin{array}{l}\text { Binds to bacterial dihydrofolate reductase and interfers with the uptake } \\
\text { of p-aminobenzoic acid(PABA) for conversion to folic acid. }\end{array}$ \\
\hline $\begin{array}{l}\text { Inhibitor of bacterial } \\
\text { translation }\end{array}$ & $\begin{array}{l}\text { Chloramphenicol } \\
\text { Amikacin }\end{array}$ & & $\begin{array}{l}\text { Binding to the } 50 \text { S ribosomal subunit and blocking the formation of the } \\
\text { peptide bond by inhibiting peptidyl transferase activity. } \\
\text { By irreversibly binding to specific } 30 \text {-subunit proteins and } 16 \mathrm{~S} \text { rRNA } \\
\text { and prevent the formation of an initiation complex with messenger RNA. }\end{array}$ \\
\hline
\end{tabular}

Table 2a: Percentage resistance to cephalosporin antibiotics in clinical isolates of Klebsiella pneumoniae

\begin{tabular}{|c|c|c|c|c|c|c|c|c|}
\hline & \multirow[b]{2}{*}{$\begin{array}{l}\text { Amp } \\
(\%)\end{array}$} & \multirow[b]{2}{*}{$\begin{array}{l}\text { Piperacillin } \\
(\%)\end{array}$} & \multicolumn{2}{|c|}{2 G cephalosporins $(\%)$} & \multicolumn{3}{|c|}{$3 \mathrm{G}$ cephalosporins $(\%)$} & \multirow[b]{2}{*}{$\begin{array}{l}\text { Amoxiclav } \\
(\%)\end{array}$} \\
\hline & & & Cefoxitin & Cefamandole & Ceftazidime & Cefotaxime & Cefoperazone & \\
\hline Urine $(\mathrm{n}=66)$ & 100 & 94 & 97 & 82 & 74 & 73 & 73 & 23 \\
\hline $\begin{array}{l}\text { Miscellaneous (pus } \\
\text { and sputum) }(\mathrm{n}=115)\end{array}$ & 100 & 100 & 89 & 70 & 66 & 63 & 68 & 10 \\
\hline Blood $(n=7)$ & 100 & 86 & 100 & 86 & 71 & 71 & 71 & 71 \\
\hline Total & 100 & 97 & 92 & 74.5 & 69 & 66 & 70 & 17 \\
\hline
\end{tabular}

Table 2b: Percentage resistance of Klebsiella pneumoniae isolates to quinolones and other antibiotics

\begin{tabular}{|c|c|c|c|c|c|c|c|}
\hline & \multicolumn{4}{|c|}{ Quinolones (\%) } & \multirow{2}{*}{$\begin{array}{l}\text { Trimethoprim } \\
(\%)\end{array}$} & \multirow{2}{*}{$\begin{array}{l}\text { Amikacin } \\
(\%)\end{array}$} & \multirow{2}{*}{$\begin{array}{l}\text { Chloramphenicol } \\
(\%)\end{array}$} \\
\hline & $\mathrm{Nal}$ & Cip & Nor & Levo & & & \\
\hline Urine $(\mathrm{n}=66)$ & 67 & 47 & 46 & 58 & 74 & 73 & 47 \\
\hline $\begin{array}{l}\text { Miscellaneous (pus and } \\
\text { sputum) }(\mathrm{n}=115)\end{array}$ & 88 & 37 & 40 & 56 & 62 & 77 & 38 \\
\hline Blood $(n=7)$ & 57 & 43 & 58 & 43 & 86 & 43 & 29 \\
\hline Total & 61 & 41 & 39 & 56 & 67 & 74 & 41 \\
\hline
\end{tabular}

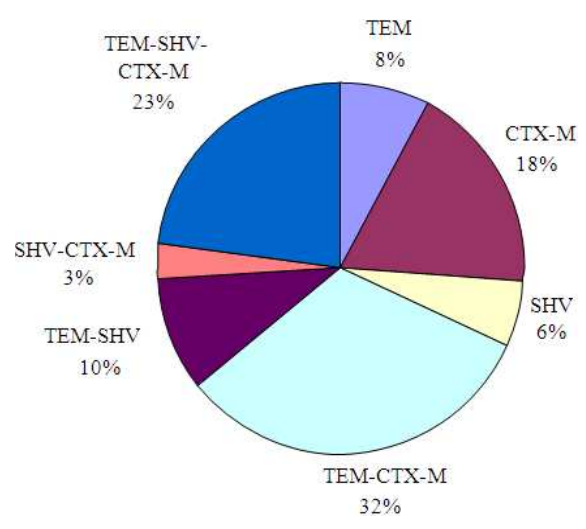

Fig. 1: Distribution of ESBL genotypes in the clinical isolates $(\mathrm{n}=152)$. Plasmids were extracted from each isolate and PCR was performed with ESBL specific primers. Isolates were scored for specific PCR amplification by agarose gel electrophoresis
Table 3: Shows the number of clones amplifying the ESBL type either alone or in combination with the other types

\begin{tabular}{ll}
\hline ESBL amplification & No. of clones $(\%)$ \\
\hline TEM & $112(73)$ \\
SHV & $65(42)$ \\
CTX-M & $116(75)$ \\
\hline
\end{tabular}

\section{DISCUSSION}

A total of 188 Klebsiella isolates from Chennai collected during one year were analyzed for their response to Cephalosporins, Quinolones, Aminoglycosides and Trimethoprim.

In the clinical isolates studied, the resistance to 2nd generation Cephalosporin antibiotics such as cephoxitin and cephamanlole was very high. The Klebsiella isolates from urinary samples showed 97 resistance to cephoxitin and $82 \%$ to cephamandole; slightly lower resistance to ceftazidin (74), cefotaxime 73 and cefoperazone $(73 \%)$. Among the isolates from sputum 
Am. J. Infect. Dis., 5 (2): 74-82, 2009

Table 4: Shows the distribution of isolates in each ESBL genotypic group. The isolates in each ESBL type were scored for their resistance to each antibiotic ( 1 for resistance and 0 for Intermediate or sensitive) and were clustered for identical patterns. No. of isolates in each cluster are indicated. Those groups which are resistant to more than two groups of antibiotics are listed as MDR. Total number of isolates were 154

\begin{tabular}{|c|c|c|c|c|c|c|c|c|c|c|c|c|c|c|c|c|}
\hline \multirow{3}{*}{$\frac{\text { ESBL type }}{\text { Only TEM }}$} & \multicolumn{2}{|c|}{ No. of isolates } & Cla & $\mathrm{Cn}$ & $\mathrm{Cm}$ & $\mathrm{Ca}$ & $\mathrm{Ce}$ & Cs & $\mathrm{Nal}$ & Cip & Nor & Lev & Tri & Ami & Chl & Isolate cho \\
\hline & \multicolumn{2}{|l|}{4} & 0 & 1 & 0 & 0 & 0 & 0 & 0 & 0 & 0 & 0 & 0 & 1 & 0 & \\
\hline & \multicolumn{2}{|l|}{8} & 0 & 1 & 1 & 0 & 0 & 0 & 0 & 0 & 0 & 0 & 0 & 1 & 0 & \\
\hline Only SHV & 10 & MDR & 0 & 1 & 1 & 1 & 1 & 1 & 1 & 1 & 1 & 1 & 1 & 0 & 1 & \\
\hline \multirow[t]{6}{*}{ Only CTX-M } & \multicolumn{2}{|l|}{1} & 0 & 1 & 1 & 1 & 1 & 1 & 1 & 0 & 0 & 1 & 1 & 1 & 0 & \\
\hline & 1 & MDR & 1 & 1 & 1 & 1 & 1 & 1 & 1 & 1 & 1 & 1 & 1 & 1 & 1 & \multirow{5}{*}{$\begin{array}{l}\text { UT1644 } \\
\text { MS3379 }\end{array}$} \\
\hline & 1 & MDR & 0 & 1 & 0 & 1 & 1 & 1 & 1 & 1 & 1 & 1 & 1 & 1 & 0 & \\
\hline & 1 & MDR & 0 & 1 & 1 & 1 & 1 & 1 & 1 & 1 & 1 & 1 & 0 & 1 & 1 & \\
\hline & 1 & MDR & 0 & 1 & 1 & 1 & 1 & 1 & 0 & 1 & 1 & 0 & 1 & 1 & 1 & \\
\hline & \multicolumn{2}{|l|}{24} & 0 & 1 & 0 & 0 & 0 & 0 & 1 & 0 & 0 & 1 & 0 & 1 & 0 & \\
\hline TEM- & 2 & MDR & 0 & 1 & 1 & 1 & 1 & 1 & 1 & 1 & 1 & 1 & 1 & 1 & 1 & \multirow[t]{5}{*}{ UT2851 } \\
\hline CTXM- & \multicolumn{2}{|l|}{1} & 0 & 1 & 1 & 1 & 1 & 1 & 0 & 0 & 1 & 0 & 1 & 0 & 1 & \\
\hline \multirow[t]{3}{*}{ SHV } & \multicolumn{2}{|l|}{26} & 0 & 1 & 1 & 1 & 1 & 1 & 0 & 0 & 0 & 0 & 1 & 1 & 1 & \\
\hline & \multirow{2}{*}{\multicolumn{2}{|c|}{$\begin{array}{l}1 \\
5\end{array}$}} & 0 & 1 & 1 & 1 & 1 & 1 & 1 & 0 & 0 & 0 & 0 & 1 & 0 & \\
\hline & & & 0 & 0 & 0 & 1 & 0 & 0 & 0 & 0 & 0 & 0 & 1 & 1 & 1 & \\
\hline \multirow[t]{4}{*}{ TEM-SHV } & 10 & MDR & 1 & 1 & 1 & 1 & 1 & 1 & 1 & 1 & 1 & 1 & 1 & 1 & 1 & \multirow{4}{*}{ UT1658 } \\
\hline & 1 & MDR & 0 & 1 & 1 & 1 & 1 & 1 & 1 & 1 & 1 & 1 & 1 & 1 & 1 & \\
\hline & 1 & MDR & 1 & 1 & 1 & 0 & 1 & 1 & 1 & 1 & 1 & 1 & 1 & 1 & 1 & \\
\hline & \multicolumn{2}{|l|}{4} & 0 & 1 & 1 & 1 & 1 & 0 & 0 & 0 & 0 & 0 & 0 & 1 & 0 & \\
\hline \multirow[t]{11}{*}{ TEM-CTX } & 1 & MDR & 1 & 1 & 1 & 1 & 1 & 1 & 1 & 1 & 1 & 1 & 1 & 1 & 1 & \\
\hline & 1 & MDR & 1 & 1 & 1 & 1 & 1 & 1 & 1 & 1 & 1 & 1 & 1 & 1 & 0 & \\
\hline & 5 & MDR & 0 & 1 & 1 & 1 & 1 & 1 & 1 & 1 & 1 & 1 & 1 & 1 & 0 & \\
\hline & 1 & MDR & 1 & 1 & 1 & 1 & 1 & 1 & 1 & 1 & 1 & 0 & 1 & 1 & 0 & \\
\hline & 8 & MDR & 0 & 1 & 1 & 1 & 1 & 1 & 1 & 1 & 1 & 1 & 1 & 0 & 0 & \\
\hline & 3 & MDR & 0 & 1 & 0 & 1 & 1 & 1 & 1 & 0 & 1 & 1 & 1 & 1 & 0 & \\
\hline & 9 & & 0 & 1 & 1 & 1 & 1 & 1 & 1 & 1 & 0 & 1 & 1 & 1 & 0 & \\
\hline & 7 & & 0 & 1 & 1 & 1 & 1 & 1 & 1 & 0 & 0 & 0 & 1 & 1 & 0 & \\
\hline & 3 & & 0 & 1 & 1 & 1 & 1 & 1 & 0 & 0 & 0 & 1 & 1 & 0 & 0 & \\
\hline & 2 & & 0 & 1 & 1 & 0 & 0 & 1 & 0 & 0 & 0 & 0 & 0 & 1 & 0 & \\
\hline & 8 & & 0 & 0 & 0 & 0 & 0 & 1 & 0 & 1 & 0 & 0 & 0 & 1 & 0 & \\
\hline SHV-CTX & 1 & MDR & 0 & 1 & 1 & 1 & 1 & 1 & 1 & 1 & 1 & 1 & 1 & 1 & 1 & \\
\hline & 2 & MDR & 0 & 1 & 1 & 1 & 1 & 1 & 1 & 1 & 1 & 1 & 1 & 1 & 0 & MS3358 \\
\hline & 1 & & 0 & 0 & 0 & 0 & 0 & 0 & 0 & 0 & 0 & 0 & 0 & 0 & 0 & \\
\hline
\end{tabular}

Table 5: The antimicrobial activity of plant extracts against the MDR isolates is shown here. The clearing zone around the plant antimicrobial disc was measured in $\mathrm{mm}$ and reported here. Plant extracts used were Punica granatum, Delonix regina, Hemidesmus indicus, Terminalia arjuna, Camellia sinensis, Holarrhena antidysentrica. Column A represent the acetone extract and column B represents the ethyl acetate extract. Plant extracts giving a significant clearing zone and antimicrobial activity are shown in bold

\begin{tabular}{|c|c|c|c|c|c|c|c|c|c|c|c|c|}
\hline \multirow[b]{2}{*}{ Isolate ID } & \multicolumn{2}{|c|}{ Punica granatum } & \multicolumn{2}{|c|}{ Delonix regina } & \multicolumn{2}{|c|}{ Hemides musindicus } & \multicolumn{2}{|c|}{ Terminalia arjuna } & \multicolumn{2}{|c|}{ Camellia sinensis } & \multicolumn{2}{|c|}{ Holarrhena antidysentrica } \\
\hline & A & B & A & B & A & B & A & B & A & B & A & B \\
\hline UT2851 & 11 & 14 & 14 & 0 & 13 & 16 & 12 & 13 & 0 & 0 & 10 & 11 \\
\hline MS3379 & 17 & 12 & 12 & 10 & 22 & 19 & 21 & 16 & 10 & 12 & 13 & 15 \\
\hline UTI658 & 13 & 12 & 11 & 12 & 16 & 18 & 18 & 19 & 0 & 16 & 10 & 11 \\
\hline MS3358 & 16 & 10 & 0 & 0 & 14 & 11 & 15 & 14 & 0 & 0 & 11 & 12 \\
\hline UTI644 & 14 & 13 & 0 & 12 & 15 & 12 & 14 & 12 & 0 & 13 & 10 & 13 \\
\hline
\end{tabular}

and pus 89 were resistant to cefoxitin, 70 to cefamandole, 66 to ceftazidine, 63 to cefotaxime and $68 \%$ to cefoperazone. The percentage resistance was higher in blood isolates with 92 resistance to cefoxitine, 74.5 to cefamandole, 69 to ceftazidine, 66 to cefotaxime and $70 \%$ to cefoperazone.

Clavulanic acid is a potent inhibitor of class a ESBL enzymes and is used in conjunction with cephalosporins. In our study we found $16.5 \%$ of the isolates were resistant to Amoxyclav, showing the increasing prevalence of clavulanic acid insensitive ESBL enzymes in Indian isolates.

We explored the use of other groups of antibiotics with a different mode of action such as the fluroquinolone group, trimethoprim, a metabolic inhibitor and chloramphenicol or amikacin which inhibit translation. We found that resistance to trimethoprim which functions by inhibiting the enzyme dyhydrofolate reductase essential for uptake of PABA was also high at $66 \%$ resistance. Among the antibiotics 
inhibiting translation amikacin which inhibits by specific 30S-subunit proteins and 16S rRNA showed $73 \%$ resistance. Chloramphenicol showed only $40 \%$ resistance but its use is confined to life-threatening diseases since it is a potent inhibitor of mitochondrial protein synthesis in eukaryotic cells.

As a group quinolones were more effective with resistance ranging from 38 for norfloxacin to $61 \%$ to nalidixic acid. Nalidixic acid is the prototype quinolone which inhibits DNA gyrase binding to DNA in Enterobacteraceae. Ciprofloxacin and norfloxacin are 1st Generation fluoroquinolones with broader activity against Gram negative bacteria. Resistance to the broad spectrum 2nd Generation fluoroquinolone drug Levofloxacin is marginally higher at 55\%. A higher resistance to levofloxacin has been reported in Singapore before its clinical use and this has been attributed to cross-resistance to other quinolones or due to the agricultural use of quinolones ${ }^{[16]}$.

From this study it emerges that the fluoroquinolone antibiotics norfloxacin and ciprofloxacin may be recommended for ESBL outbreaks. However incidences of these two antibiotics are also on the raise.

Resistance to beta lactam antibiotics is due to the presence of ESBL genes which can be various types. The specific ESBL gene present in each isolate was identified by specific PCR. We found that CTX-M type was most prevalent being preent in 75 isolates followed by TEM in 73 and SHV type in $42 \%$. The SHV isolates were resistant to all the cephalosporin antibiotics used. The TEM isolates were sensitive to the 3rd Generation cephalosporins, though there may be two subtypes differing in their sensitivity to cefamandole. The CTX$\mathrm{M}$ isolates appear to have two subtypes differing in their sensitivity to the 3rd generation cephalosporins. The substrate specificity of the ESBL subtypes are due to amino acid substitutions which lead to evolution of different subtypes.

SHV-type ESBL were the first enzymes reported beta-lactamase $^{[17]}$ and resistant to cefotaxime, cefoxitin, cefamandole were originally chromosomal but now found in plasmids. The SHV ESBL are prevalent in USA, Europe and Latin America. TEM type ESBLs have been found to be predominant in Italy and France $^{[18]}$. The CTX-M-encoding genes are believed to have been captured from the chromosome of Kluyvera spp. on conjugative plasmids that mediate their dissemination among pathogenic enterobacteria. Recent reports have suggested that CTX-M is prevalent in Asia and could represent a major reservoir for CTX-M gene $^{[19]}$. In a study in Thailand, $99.2 \%$ of ESBL Klebsiella pneumoniae contained CTX-M gene ${ }^{[2]}$. In India studies have suggested a high incidence of CTX-
M-15 gene in clinical isolates ${ }^{[20]}$ and there has recently been a report of the sequencing of CTX-M-28 ESBL gene $^{[21]}$. The CTX-M-15 were isolated in 1999 from patients hospitalized in a New Delhi hospital and is likely to be endemic to India ${ }^{[22]}$.

Our data suggest that TEM and CTX-M are higher in the Chennai population compared to the SHV type. However the SHV types are correlated with resistance to even the 3rd generation cephalosporins. The isolates with 2 or more ESBL types could have emerged due to recombination between the ancestral plasmids or transposition of the drug resistance genes. We found a high frequency of isolates containing the combination of CTX-M and TEM. Though the clones containing SHVTEM were only 10 they correlated with the amoxuclav resistant clavulanic acid sensitive, MDR isolates.

The clustering of the Klebsiella isolates based on the ESBL typing and response to 15 different antibiotics gave us a method to presumptively identify clonal spreads. We identified 4 prevalent clones based on this method: One group with TEM, SHV, CTX-M ESBL, resistant to all cephalosporns, trimethoprim, chloramphenicol and amikacin but susceptible to quinolones. Next clone has only CTX-M ESBL and is resistant to cephalosporins but susceptible to all the other group of antibiotics used. Next are the highly MDR isolates with only SHV ESBL resistant to all antibiotics except amikacin; and the last with TEM-SHV ESBL which were resistant to all antibiotics used and were clavulanic acid insensitive. These two clones are highly resistant and must be checked from further spread.

Among the other isolates 14 other groups were identified as MDR of which 5 were insensitive to clavulanic acid. These isolates are likely to harbor plasmids which have resistance genes for more all antibiotics and are therefore highly pathogenic. Those which are resistant to all the antibiotic groups are also candidates for mutations in the drug efflux pumps since this can give high resistance to drugs.

In our study we found the isolates containing SHV ESBL type were the most pathogenic and were highly resistant, followed by CTX-M type which shows coresistance to a few quinolones and amikacin. The least pathogenic were the isolates containing TEM type ESBL which were resistant to only $2 \mathrm{G}$ cephalosproins and amikacin.

Restriction analysis of chosen MDR isolates: All the Klebsiella isolates in this study contained plasmids harboring resistanace genes (Fig. 2). We analyzed the restriction pattern of three isolates by BamHI and HindIII and found that the pattern was different suggesting the plasmids were different (Fig. 3). 
Am. J. Infect. Dis., 5 (2): 74-82, 2009

Table 6: List of MDR clinical isolates analyzed by restriction patterns and effect of plant antimicrobials and summary of the results

\begin{tabular}{|c|c|c|c|c|}
\hline Isolate name & ESBL & Resistance & Restriction pattern & Sensitivity to plant antimicrobials \\
\hline UT1644 & CTX-M & $\mathrm{MDR}, \mathrm{Cla}^{\mathrm{r}}$ & 15 bands with HindIII & Resistant to plant antimicrobials \\
\hline MS3379 & CTX-M & $\mathrm{MDR}, \mathrm{Cm}^{\mathrm{s}}, \mathrm{Chl}^{\mathrm{s}}, \mathrm{Cla}^{\mathrm{s}}$ & $\mathrm{Nd}$ & Sensitive to plant antimicrobials \\
\hline UT2851 & CTX-M, TEM & $\mathrm{MDR}, \mathrm{Cla}^{\mathrm{s}}$ & 8 bands with HindIII & Resistant to plant antimicrobials \\
\hline UT1658 & TEM, SHV & MDR Cla ${ }^{\mathrm{s}}$ & $\mathrm{Nd}$ & Sensitive to plant antimicrobials \\
\hline MS3358 & SHV, CTX & $\mathrm{MDR}, \mathrm{Chl}^{\mathrm{s}}, \mathrm{Cla}^{\mathrm{s}}$ & $\mathrm{Nd}$ & Resistant to plant antimicrobials \\
\hline $\mathrm{U} 28810$ & Not done & $\mathrm{MDR}, \mathrm{Cla}^{\mathrm{r}}$ & 9 bands with HindIII & Not tested \\
\hline
\end{tabular}

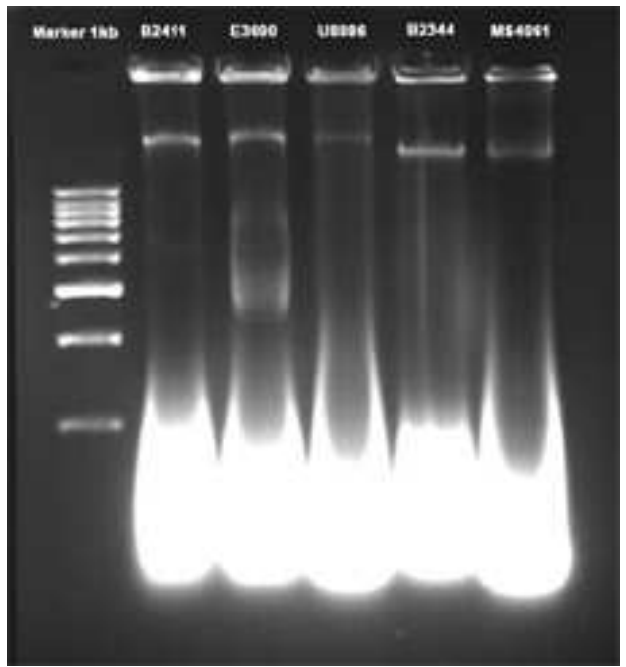

Fig. 2: $0.7 \%$ Agarose gel analyzing plasmids extracted from a few MDR cultures
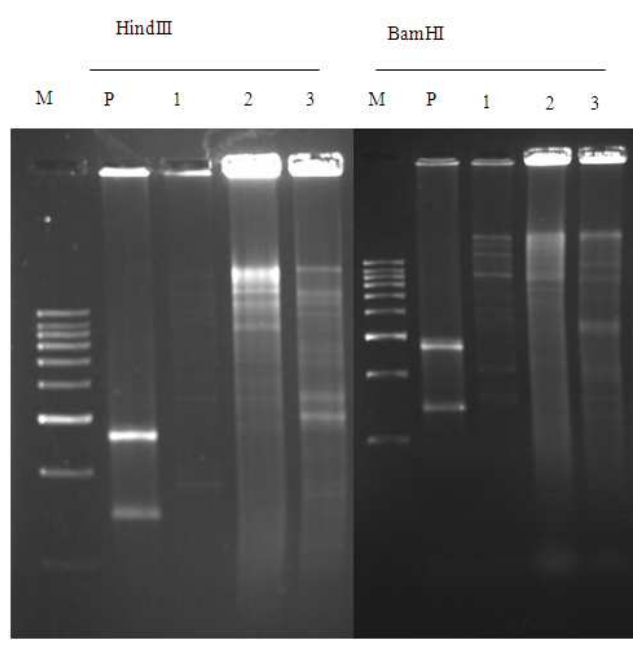

Fig. 3: Plasmids were extracted from 3 MDR strains and digested with BamHI or HindIII and electrophoresed on a $0.7 \%$ agarose gel. As a control pUC 18 plasmid was used. $\mathrm{M}-1 \mathrm{~Kb}$ Marker, P-pUC 18, (1): UT2851-CTX-M, TEM, SHV, MDR, cla s, (2): U28810 MDR, Cla r, (3): UT1644 CTX-M, MDR cla r
Numerous different types of plasmids have been isolated from Klebsiella including pMET1, a $41 \mathrm{~Kb}$ multi-resistance plasmid. Further characterization of the plasmids present in the Indian isolates will be very valuable due to the large size of the Indian population and its potential to spread to other countries.

Search for plant products effective against MDR strains: There have been numerous reports that plant compounds can be lead compounds in the identification of new antimicrobial drugs. Therefore we decided to test a few plants against a few chosen MDR strains. Some plants have been shown to possess MDR pump inhibitor which can potentiate the activity of plant antimicrobials.

Out of the plant antimicrobials tested, the extracts of Hemidesmus indicus and Terminalia arjuna showed antimicrobial activity against two of the isolates used. The results of restriction pattern analysis, sensitivity to plant extracts and antibiotic resistance profiles of a few chosen strains is presented in Table 6. Our data suggest that the each of the MDR strains may be harboring a different plasmid and each might have different mechanisms of antibiotic resistance. The effect of plant antimicrobial extracts on these strains must be analyzed further to identify the bioactive principle.

\section{CONCLUSION}

Towards the search for newer antimicrobials it is important to identify the specific mechanism and genes conferring antibiotic resistance in prevalent MDR strains. Further, the identification of the bioactive principle by separation and activity testing is important for developing plant based antimicrobials.

\section{REFERENCES}

1. Podschun, R. and U. Ullmann, 1998. Klebsiella spp. as nosocomial pathogens: Epidemiology, taxonomy, typing methods and pathogenicity factors. Clin. Microbiol. Rev., 11: 589-603. http://www.ncbi.nlm.nih.gov/pubmed/ 9767057 
2. Kiratisin, P., A. Apisarnthanarak, C. Laesripa and P. Saifon, 2008. Molecular characterization and epidemiology of extended-spectrum-betalactamase-producing Escherichia coli and Klebsiella pneumoniae isolates causing health careassociated infection in Thailand, where the CTX-M family is endemic. Antimicrob Agents Chemother., 52: 2818-2824.

http://www.ncbi.nlm.nih.gov/pubmed/ 18505851

3. Kusum, M., W.S. Dhiraputra, P. Pongpech and P. Naenna, 2004. Occurrence of extendedspectrum beta-lactamase in clinical isolates of Klebsiella pneumoniae in a University Hospital, Thailand. J. Med. Assoc. Thai., 87: 1029-1033. http://www.ncbi.nlm.nih.gov/pubmed/15516002

4. Xiong, Z., Y. Zhang and F. Wang, 2002. Extendedspectrum beta-lactamase in Klebsiella pneumoniae and Escherichia coli isolates. Zhonghua Yi Xue Za Zhi, 82: 1476-1479.

http://www.ncbi.nlm.nih.gov/pubmed/12509910.

5. Wang, A.Y.Y., Q. Lu, Y. Wang, Y. Chen, L. Deng, H. Ding, Q. Deng, L. Wang and X. Shen, 2008. Occurrence of qnr-positive clinical isolates in Klebsiella pneumoniae producing ESBL or AmpCtype beta-lactamase from five pediatric hospitals in China. FEMS. Microbiol. Lett., 283: 112-116.

http://www.ncbi.nlm.nih.gov/pubmed/18422623.

6. Jiang, Y.Z.Z., Y. Qian, Z. Wei, Y. Yu, S. Hu and L. Li, 2008. Plasmid-mediated quinolone resistance determinants qnr and aac(6')-Ib-cr in extendedspectrum beta-lactamase-producing Escherichia coli and Klebsiella pneumoniae in China. J. Antimicrob. Chemother., 61: 1003-1006. http://www.ncbi.nlm.nih.fov/pubmed/18299311

7. Mascaretti, O.A., 2003. Bacteria Versus Antibacterial Agents: An Integrated Approach. ASM Press, ISBN: 1555812589, pp: 393.

8. Schneiders, T., S.G.B. Amyes and S.B. Levy, 2003. Role of AcrR and RamA in fluoroquinolone resistance in clinical Klebsiella pneumoniae isolates from Singapore. Antimicrob Agents Chemother., 47: 2831-2837. DOI: 10.1128/aac.47.9.2831-2837.2003

9. Martinez-Martinez, L., A. Pascual and G.A. Jacoby, 1998. Quinolone resistance from a transferable plasmid. Lancet, 351: 797-799. http://www.ncbi.nlm.nih.gov/pubmed/ 9519952

10. Tolmasky, M.E.R.M.C., J.H. Crosa and P.M. Marini, 1988. Transposon-mediated amikacin resistance in Klebsiella pneumoniae. Antimicrob Agents Chemother., $\quad 32$ : 1416-1420. http://www.ncbi.nlm.nih.gov/pubmed/ 2848445
11. Bauer, A., W. Kirby, J. Sherris and M. Turck, 1966. Antibiotic susceptibility test by a standardized single disc method. Am. J. Clin. Pathol., 45: 493-496. http://www.ncbi.nlm.nih.gov/pubmed/5325707

12. Wikler, M.A., 2004. Performance Standards for Antimicrobial Susceptibility Testing: Fourteenth Informational Supplement. 14 Edn., National Committee Clinical Laboratory Standards (NCCLS), ISBN: 9781562385163, pp: 159.

13. Yu, W.L., P.L. Winokur, D.L. Von Stein, M.A. Pfaller, J.H. Wang and R.N. Jones, 2002. First description of Klebsiella pneumoniae harboring CTX-Mlactamases (CTX-M-14 and CTX-M-3) in Taiwan. J. Antimicrob Chemother., 46: 1098-1100. DOI: 10.1128/AAC.46.4.1098-1100.2002

14. Sambrook, J. and D. Russell, 2001. Molecular Cloning-A Laboratory Manual. 3rd Edn., Cold Spring Harbor Laboratory Press, pp: 2100.

15. Baik, H.S., T.U. Kim and Y. Tae, 2006. Characterization of extended spectrum betalactamase genotype TEM, SHV and CTX-M producing Klebsiella pneumoniae isolated from clinical specimens in Korea. J. Microbiol. Biotechnol., 16: 889-895.

http://www.jmb.or.kr/home/journal/library/article_ view.asp? articleuid $=\{146 \mathrm{BA} 275-\mathrm{D} 978-4088$ 900C-9BD8E58A7B63\}

16. Kumarasinghe, G., C. Chow and P.A. Tambyah, 2000. The emergence of resistance to levofloxacin before clinical use in a university hospital in Singapore. J. Antimicrob Chemother., 46: 862-863. http://www.ncbi.nlm.nih.gov/pubmed/11062223

17. Knothe, H., P. Shah, V. Krcmery, M. Antal and S. Mitsuhashi, 1983. Transferable resistance to cefotaxime, cefoxitin, cefamandole and cefuroxime in clinical isolates of Klebsiella pneumoniae and Serratia marcescens. Infection, 11: 315-317. http://www.ncbi.nlm.nih.gov/pubmed/6321357

18. Perilli, M., E. Dell'Amico, B. Segatore, M.R. de Massis, C. Bianchi, F. Luzzaro, G.M. Rossolini, A. Toniolo, G. Nicoletti and G. Amicosante, 2002. Molecular characterization of extended-spectrum betalactamases produced by nosocomial isolates of Enterobacteriaceae from an Italian nationwide survey. J. Clin. Microbiol., 40: 611-614. DOI: 10.1128/jcm.40.2.611-614.2002

19. Hawkey, P.M., 2008. Prevalence and clonality of extended-spectrum beta-lactamases in Asia. Clin. Microbiol. Infect., 14: 159-165. http://www.ncbi.nlm.nih.gov/pubmed/18154540 
20. Muzaheed, Y.D., J.M. Adams-Haduch, A. Endimiani, H.E. Sidjabat, S.M. Gaddad and D.L. Paterson, 2008. High prevalence of CTX-M-15-producing Klebsiella pneumoniae among inpatients and outpatients with urinary tract infection in Southern India. J. Antimicrob. Chemother., 61: 1393-1394. DOI: $10.1093 / \mathrm{jac} / \mathrm{dkn} 109$

21. Kingsley, J. and S. Verghese, 2008. Sequence analysis of bla CTX-M-28, an ESBL responsible for third-generation cephalosporin resistance in Enterobacteriaceae, for the first time in India. Indian J. Pathol. Microbiol., 51: 218-221. http://www.ncbi.nlm.nih.gov/pubmed/18603686
22. Karim, A., L. Poirel, S. Nagarajan and P. Nordmann, 2001. Plasmid-mediated extended-spectrum betalactamase (CTX-M-3 like) from India and gene association with insertion sequence ISEcp1. FEMS Microbiol. Lett., 201: 237-241. http://www.ncbi.nlm.nih.gov/pubmed/11470367 